УДК 004.94

https://doi.org/10.36906/AP-2020/17

\title{
DEVELOPMENT OF AUGMENTED REALITY MOBILE APPLICATION ON ANDROID OS
}

\author{
Galeeva A. M. \\ Kazan Federal University \\ Kazan, Russia \\ Medvedeva O. A. \\ Ph.D., \\ Kazan Federal University \\ Kazan, Russia
}

\begin{abstract}
The article describes the use of augmented reality technologies in the modern educational process to increase educational motivation, multimedia and interactivity of the lecture material. The main purpose of the application: educational and cognitive. In the process of performing work, computer graphics, algorithms and modeling methods were used. Use case: there are special images on the stand that the mobile application recognizes and shows the created 3D models of the "Sun" and "Milky Way". In addition, while the 3D model is being displayed, a short training audio lecture will be held. To create a 3D model of objects, the Unity program was used in conjunction with the augmented reality platform Vuforia.
\end{abstract}

Keywords: augmented reality, OS Android, Vuforia, Unity, mobile application.

In educational settings, AR has been used to complement a standard curriculum. Text, graphics, video, and audio may be superimposed into a student's real-time environment. Textbooks, flashcards and other educational reading material may contain embedded "markers" or triggers that, when scanned by an AR device, produced supplementary information to the student rendered in a multimedia format. The Virtual, Augmented and Mixed Reality: International Conference mentioned Google Glass as an example of augmented reality that can replace the physical classroom. First, AR technologies help learners engage in authentic exploration in the real world, and virtual objects such as texts, videos, and pictures are supplementary elements for learners to conduct investigations of the real-world surroundings. As AR evolves, students can participate interactively and interact with knowledge more authentically. Instead of remaining passive recipients, students can become active learners, able to interact with their learning environment. Computer-generated simulations of historical events allow students to explore and learning details of each significant area of the event site. In higher education, Construct3D, a Studierstube system, allows students to learn mechanical engineering concepts, math or geometry. Chemistry AR apps allow students to visualize and interact with the spatial structure of a molecule using a marker object held in the hand. Others have used HP Reveal, a free app, to create AR notecards for studying organic chemistry mechanisms or to create virtual demonstrations of how to use laboratory instrumentation. Anatomy students can visualize different systems of the human body in three dimensions. Using AR as a tool to learn anatomical structures has been shown to increase the learner knowledge and provide intrinsic benefits, such as increased engagement and learner immersion [1-9]. 
A key measure of AR systems is how realistically they integrate augmentations with the real world. The software must derive real world coordinates, independent of camera, and camera images. That process is called image registration, and uses different methods of computer vision, mostly related to video tracking. Many computer vision methods of augmented reality are inherited from visual odometry. An augogram is a computer generated image that is used to create AR. Augography is the science and software practice of making augograms for AR.

Usually those methods consist of two parts. The first stage is to detect interest points, fiducial markers or optical flow in the camera images. This step can use feature detection methods like corner detection, blob detection, edge detection or thresholding, and other image processing methods. The second stage restores a real world coordinate system from the data obtained in the first stage. Some methods assume objects with known geometry (or fiducial markers) are present in the scene. In some of those cases the scene 3D structure should be calculated beforehand. If part of the scene is unknown simultaneous localization and mapping (SLAM) can map relative positions. If no information about scene geometry is available, structure from motion methods like bundle adjustment are used. Mathematical methods used in the second stage include: projective (epipolar) geometry, geometric algebra, rotation representation with exponential map, kalman and particle filters, nonlinear optimization, robust statistics.

In augmented reality, the distinction is made between two distinct modes of tracking, known as marker and markerless. Markers are visual cues which trigger the display of the virtual information. A piece of paper with some distinct geometries can be used. The camera recognizes the geometries by identifying specific points in the drawing. Markerless tracking, also called instant tracking, does not use markers. Instead, the user positions the object in the camera view preferably in a horizontal plane. It uses sensors in mobile devices to accurately detect the real-world environment, such as the locations of walls and points of intersection. Augmented Reality Markup Language (ARML) is a data standard developed within the Open Geospatial Consortium (OGC), which consists of Extensible Markup Language (XML) grammar to describe the location and appearance of virtual objects in the scene, as well as ECMAScript bindings to allow dynamic access to properties of virtual objects. To enable rapid development of augmented reality applications, some software development kits (SDKs) have emerged.

The structure of the visualization system by means of augmented reality implies the presence of the following basic components (figure 1):

1. Tracking subsystem that provides correct integration of a virtual object into a real environment.

2. Storage of three-dimensional models and other information on objects.

3. Visualization subsystem that provides drawing of objects by means of computer graphics.

4. A graphical interface that provides user interaction.

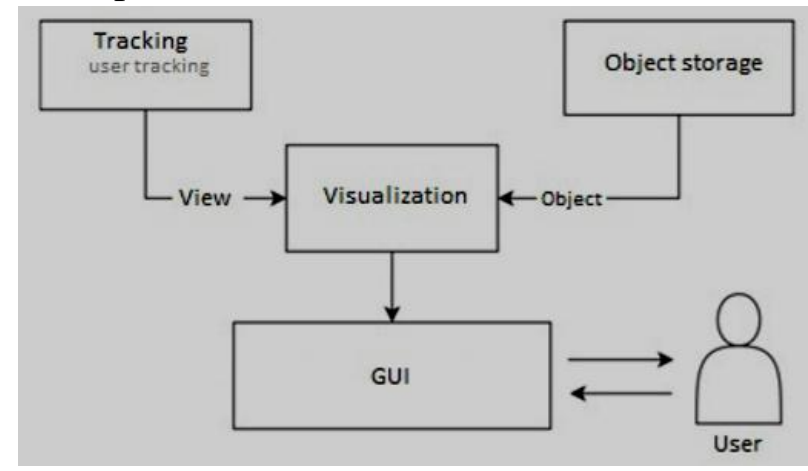

Fig. 1. Key elements of augmented reality visualization system 


\section{СОВРЕМЕННОЕ ПРОГРАММИРОВАНИЕ}

III Международная научно-практическая конференция

This article describes the development of augmented reality applications. The main purpose of the application: educational and cognitive. Theme of the application: space. Use case: on the stand there are special images that the application will recognize and show the created 3D model. Also, while the 3D model is being displayed, a short training lecture will be played. Images that the application recognizes are presented in Figure 2 and Figure 3.

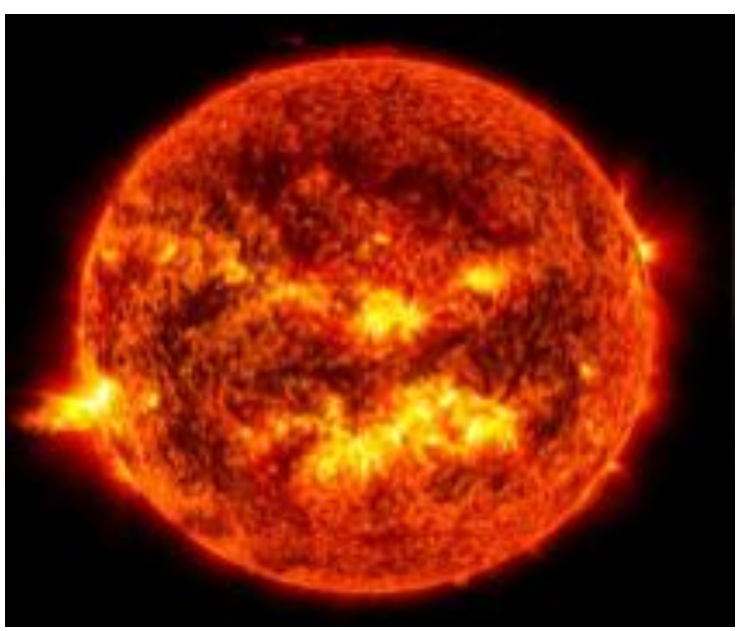

Fig. 2. Image Sun

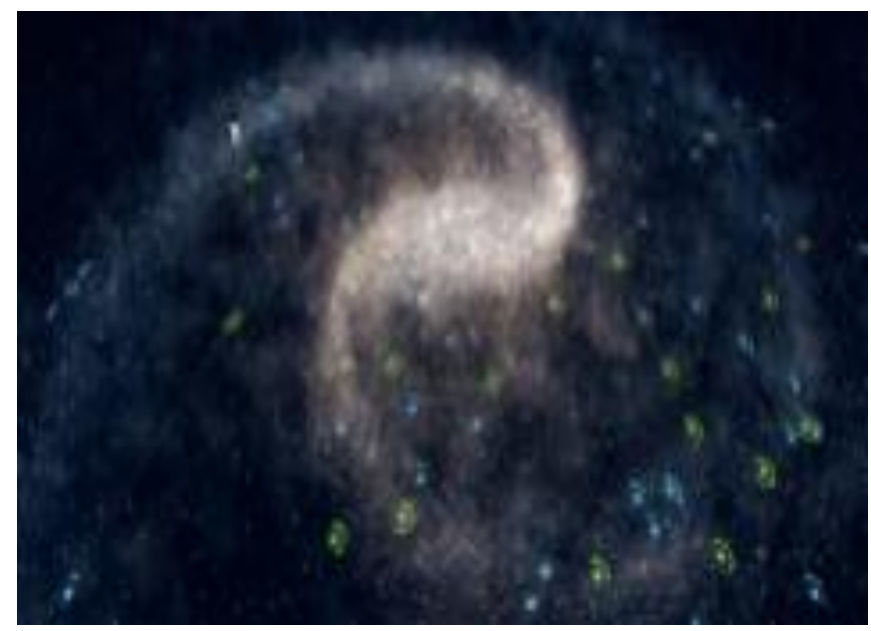

Fig. 3. Image Galaxy

To create a 3D model of objects, the Unity program was used in conjunction with the augmented reality platform Vuforia.

The following objects were used to create the "Sun" model:

- PSunSurface — is responsible for ensuring that all other objects are collected together;

- PSCorona - simulates the crown of the Sun;

- PSLoop - models light rings (radiation) around the Sun;

- SunSphere - responsible for the model of the sphere of the Sun;

- ImageTarget — responsible for a special image;

- ARCamera - is responsible for visualizing the device's camera;

- $\quad$ PSLoop, PSCorona - created using the Particle System effect;

- Configure PSCorona (Figure 4.):

- Duration - effect duration;

- Looping — repeat Effect;

- Prewarm - the effect starts playing immediately upon hovering over the picture;

- Emission - the number of particles formed in 1 second. 


\section{СОВРЕМЕННОЕ ПРОГРАММИРОВАНИЕ}

\section{III Международная научно-практическая конференция}
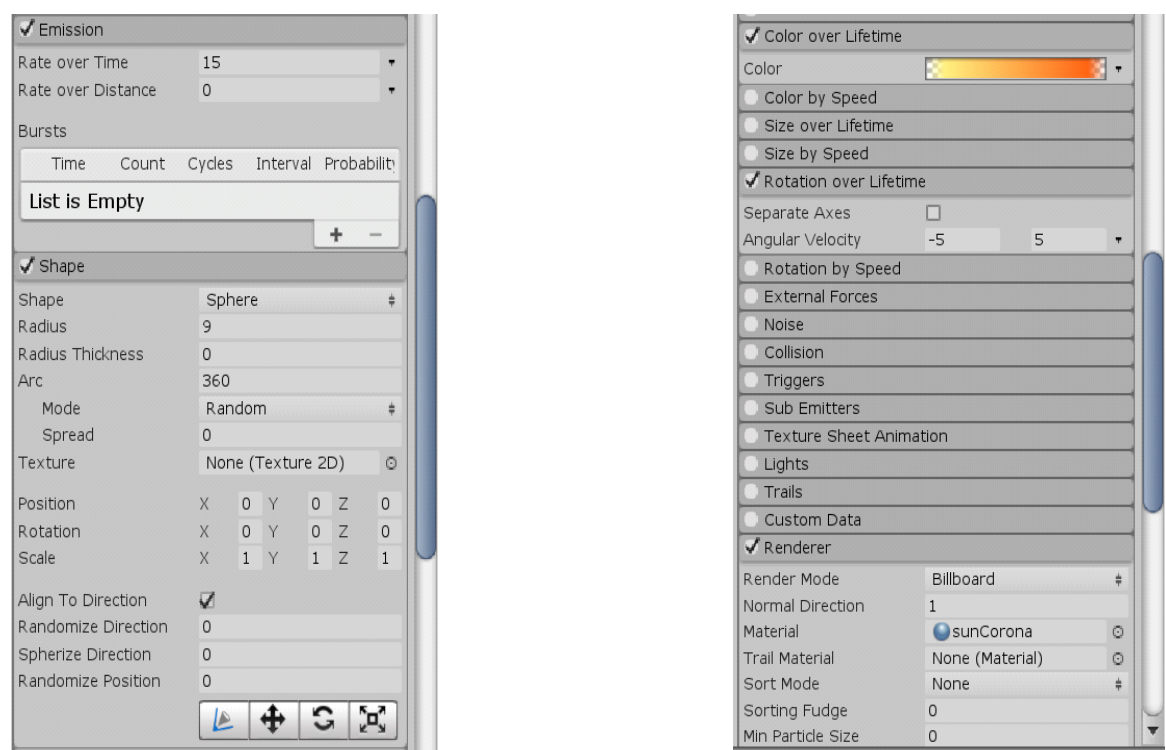

Fig. 4. Configure PSCorona

The material used to create the crown is shown in Figure 5. To create it you need to find a suitable image of smoky rings. You should import it into the project, and then select Shader Particles/Standard Unlit. After that you need to create the material in the project, insert the selected image into the oAlbedo parameter. In the same place you should select the orange color.

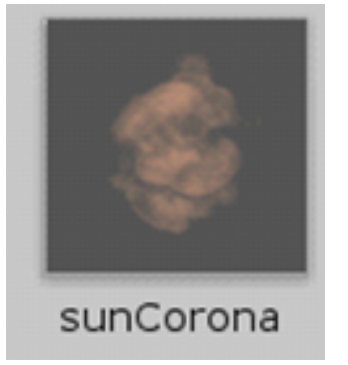

Fig. 5. The material used to create the crown

Practicing the possibility of augmented reality in education can restore the process for the visual perception of the necessary information. The article based on examples of using augmented reality technology. The possibility of using this technology in the educational environment for the visual modeling of educational material, supplementing it with visual information, while developing spatial representations, imagination, volumetric design skills, which saves teachers and students time on the transfer and assimilation of educational information, and accelerates the learning process. The application can be downloaded from the link: https://clck.ru/T7cXj.

Augmented reality technology can be applied in a large number of solutions for the educational process, for example: replacing real experiments with virtual ones in case it is not possible to work with equipment or part of it; adding three-dimensional objects to interactive teaching aids; presenting interactive information on whiteboards in classrooms without having to replace them with expensive ones; introducing interactive assistants to the educational process; learning foreign languages by replacing the words being studied with virtual objects, etc. 


\section{References}

1. Bay H., Tuytelaars T., Van Gool L. Surf: Speeded up robust features // European conference on computer vision. Springer, Berlin, Heidelberg, 2006. P. 404-417. https://doi.org/10.1007/11744023_32

2. Bimber O., Raskar R. Modern approaches to augmented reality // ACM SIGGRAPH 2006 Courses. 2006. P. 1-es. https://doi.org/10.1145/1185657.1185796

3. Bowman D. A. et al. New directions in 3d user interfaces // International Journal of Virtual Reality. 2006. Vol. 5. №2. P. 3-14. https://doi.org/10.20870/IJVR.2006.5.2.2683

4. Галеева А. М., Мустафина С. И., Медведева О. А. Разработка мобильного приложения дополненной реальности в образовательных целях // Информационные технологии и нанотехнологии (ITNT-2020): материалы VI Международной конференции. Самара. 2020. C. 1030-1038.

5. Aleksandrovich G. R. et al. Information system development using augmented reality tools // CEUR Workshop Proceedings. 2019. http://ceur-ws.org/Vol-2525/ITTCS-19_paper_16.pdf

6. Handheld Augmented Reality // Christian Doppler Laboratory on Handheld Augmented https://handheldar.icg.tugraz.at/

7. Kurz D., Benhimane S. Gravity-aware handheld augmented reality // 2011 10th IEEE International Symposium on Mixed and Augmented Reality. IEEE, 2011. P. 111-120. https://doi.org/10.1109/ISMAR.2011.6092376

8. Lee K. Augmented reality in education and training // TechTrends. 2012. Vol. 56. №2. P. 13-21. https://doi.org/10.1007/s11528-012-0559-3

9. Yasumuro Y. et al. Consistent Presentation of Interactive Virtual Objects in Real Space with 3D Markers-Interactive Virtual Interior Design- // Digital Image Computing: Techniques and Applications, Proceedings of the VIIth Biennial Australian Pattern Recognition Society Conference. 2003. P. 653-662.

(CGaleeva A. M., Medvedeva O. A., 2020 